BANGLADESH JOURNAL OF SCIENTIFIC AND INDUSTRIAL RESEARCH

E-mail: bjsir07@gmail.com

\title{
Comparative Study on the Material Selection Process for Rickshaw Frames by Weighted Property Method Using Modified Digital Logic and Analysis of Failure
}

\author{
M. H. Khan* and M. N. Islam \\ Metallurgy Division, Institute of Mining, Mineralogy and Metallurgy, Joypurhat, BCSIR, Bangladesh
}

\begin{abstract}
Systematic approaches on the material selection for rickshaw frames were applied by cost per unit and weighted property method using modified digital logic. Ashby's material selection charts were used for preliminary material selection and relative cost analysis. Physical and mechanical properties and the main failure parameters were identified in the frames. Fatigue, associated with corrosion and impact load were identified as the causes of failure for the rickshaw frames. Stress analysis on the frame system was done and for the preliminary selection of materials, the constraints were identified through mathematical models. Magnesium alloy, Titanium alloy, Steel, Aluminum alloy, CFRP, KFRP and GFRP came out from the initial selection. Among the preliminary selected materials, CFRP attained the highest performance index. However, commonly used steel was found to be the optimum for rickshaw frames in terms of figure of merit followed by aluminum alloy and KFRP.
\end{abstract}

Key words: Material selection, Rickshaw frame, Weighted property, Digital logic, Failure analysis

\section{Introduction}

Rickshaw is the most common form of vehicle in Bangladesh and is also a well established human power vehicle of the subcontinent. There are almost half million rickshaws only in the capital Dhaka of Bangladesh (Menchetti and Hendrikkade, 2005). Frames are the most important part of a rickshaw as it carries the different loads and also have to be rigid; onto which the rickshaw body and wheels are attached. Mild steel is the most available options and still, is the only component used in all the rickshaw frames. But, due to its higher specific density, the rickshaw becomes heavier and increases the hardship of the rickshaw pullers.

Around 80000 materials are available to the engineers (Farag, 2002). Material selection process would be a tedious job and many materials would be overlooked if the selection was done haphazardly. Hence, a systematic selection process is required which has been established over the years. The first step in the material selection process, probably, is to identify the performance requirement and hence, selecting the cardinal properties requirement in that application. From these property conditions, an initial screening of materials is done. For the quantitative method of initial screening, cost per unit property method, Ashby's material selection chart, and Dargie's method are a useful tool for selecting a set of materials (Farag, 2002). Recently, Ashby also has proposed the selection step into four basic steps: requirements, screening, ranking, searching for supported information, and based on these, final selection of the material and process (Ashby et al, 2004).

After narrowing down the field of possible materials, a number of knowledge based and integrated data based system is available for selecting the material (Ashby et al., 2004; Farag et. al 1992). Another approach may be weighted property method (WPM) or digital logic model, which essentially give the performance index from simple mathematics (Ashby, 1992; Jahazi et al., 2004; Maleque et al., 2010). In the present study, cost per unit property method and Ashby's material selection chart has been used for initial screening and weighted property method has been considered for optimum material selection. The main purpose of the present work is to evaluate the possibility of substituting the available mild steel in the rickshaw frame, thus reducing the rickshaw weight and getting the optimum performance.

\section{Materials and Methods}

Different failure parts of the rickshaw frame were collected from the local sources. The frames were inspected visually and macroscopically; care was taken to avoid damage of the fractured surfaces. For the micro structural analysis, samples 
were observed in metallurgical microscope. Failure analyses of those samples were done with the assistance of scanning electron microscope (SEM). The performance of a specific material can be expressed as [Ashby, 1992],

$\mathrm{P}=\mathrm{f}_{1}$ (Functional requirements, $\left.\mathrm{F}\right)$. $\mathrm{f}_{2}$ (Geometric requirements, $G$ ). $f_{3}$ (Material properties, $M$ )

If the geometry is kept constant, the performance depends totally on the material properties. Thus, performance can be maximized by increasing the performance index, $\mathrm{M}$ which strictly depends on the properties of materials.

Getting the conditions of performance index through mathematical calculations and thus looking in the Ashby's 'Young's modulus versus density' material selection chart, an initial set of material selection was done. The selection can be furthered narrowed down through the cost per unit strength analysis. Performance index was then established through the weighted property method and an approximate figure of merit was also calculated.

\section{Mathematical modeling}

The major forces that are subjected to rickshaw frame can be shown by the Figure (1). The objective is to obtain the minimum mass and, compression, performance index criterions has been established on this basis.

\section{Bending on shaft}

From the elastic beam theory (Pytel et al., 1987),

$$
S=\frac{C E I}{l^{8}}
$$

Where $\mathrm{C}$ is a constant, $\mathrm{E}$ is modulus of elasticity, I is the moment of inertia and length of the shaft is

L. For circular cross section, $I=\frac{\pi r^{4}}{4}$;

Hence, from equation (2), $S=\frac{C E}{l^{8}}\left(\frac{\pi r^{4}}{4}\right)=\frac{A^{2} C E}{4 \pi l^{8}}$

Therefore, $A=\left(\frac{4 \pi S}{C E}\right)^{1 / 2} l^{3 / 2}$

From equation (1),

$m=\left(\frac{4 \pi S}{c}\right)^{1 / 2}\left(l^{5 / 2}\right)\left(\frac{\rho}{E^{1 / 2}}\right)$

The performance maximizing criterion or the performance index,
Loadson

rickshaw frame

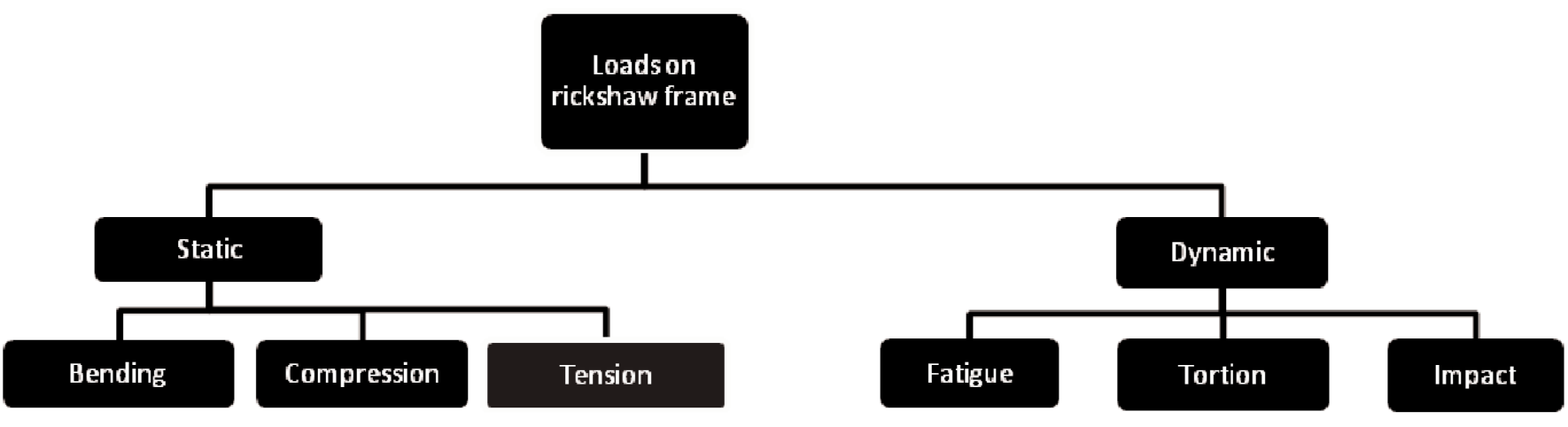

Fig. 1: Forces acting on the rickshaw frame

Mass, $m=A l \rho$

As the length will be fixed, lowering the area and the density gives the minimum mass. Hence, making a circular shape, which gives the lowest area and also selecting a lower density material can effectively reduce the mass. Figure (2) is a representation of the rickshaw frames and the loads acting on it. As the main forces acting on the frames are bending and

\section{Compression or buckling load on tubes:}

The maximum Euler's load to withstand by the column

without buckling (Pytel et al.), $F_{\text {euler }}=\frac{\pi^{2} E I}{L \theta^{2}}$

Where, $\mathrm{Le}=$ effective length $=\mathrm{cl}$; here $\mathrm{c}$ is a constant and depends on the end condition.

Now, by considering an appropriate safety factor, 


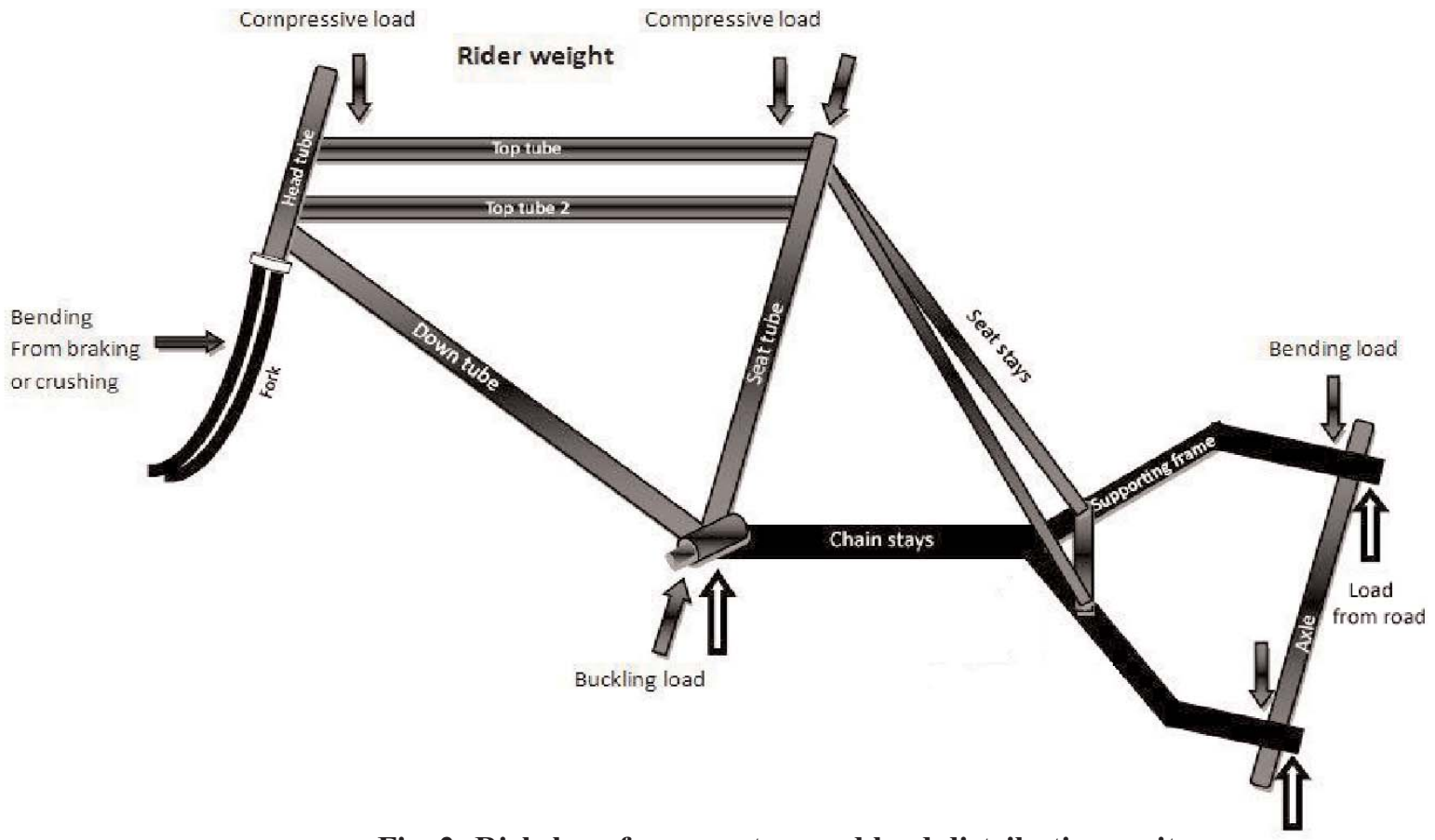

Fig. 2: Rickshaw frame system and load distribution on it.

Load, $F=\frac{F_{\text {euler }}}{S_{f}}=\frac{\pi^{2} E I}{S_{f} L e^{2}}=\frac{\pi^{2} E}{S_{f} c^{2} L^{2}}\left(\frac{\pi r^{4}}{4}\right)$

Thus, from equation (3), $A=2 c\left(\frac{F S_{f}}{\pi B}\right)^{1 / 2} l$

And, from equation (1),

$m=2 c\left(\frac{F S_{f}}{\pi}\right)^{1 / 2}\left(l^{2}\right)\left(\frac{\rho}{B^{1 / 2}}\right)$

Performance index, thus,

$$
M_{2}=\frac{E^{1 / 2}}{\rho}
$$

\section{Results and Discussion}

\section{Failure analysis of the rickshaw frames}

Failure mainly occurs in the top tube, in the forks and in the axle of a rickshaw. Impact on the fork by sudden braking or crushing or from the rough road, can cause failure in the forks. Microstructural observation was conducted on the different parts of the rickshaw and from Figure 3; we can make some approximate ideas of the structural, compositional and manufacturing condition. Thus, top tubes are seen having made of dead soft steel; seat stays are normalized mild steel; the supporting frames are cold worked dead soft steel and the axle is cold rolled mild steel.

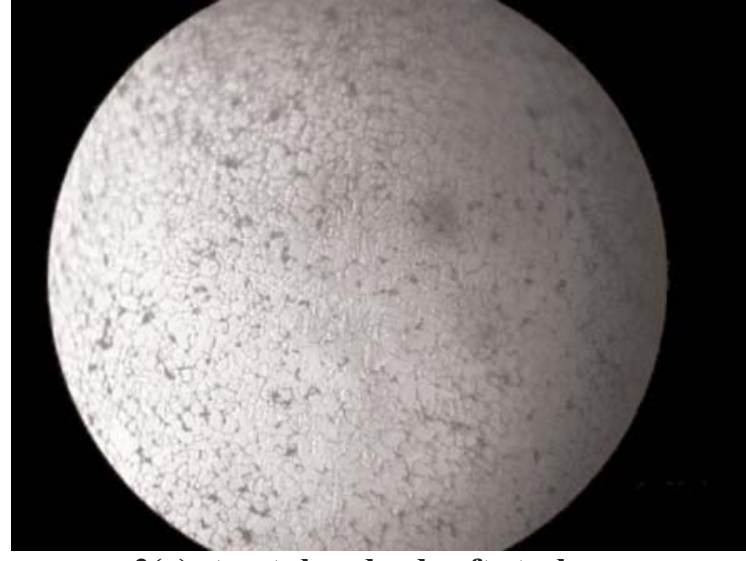

3(a): top tube: dead soft steel

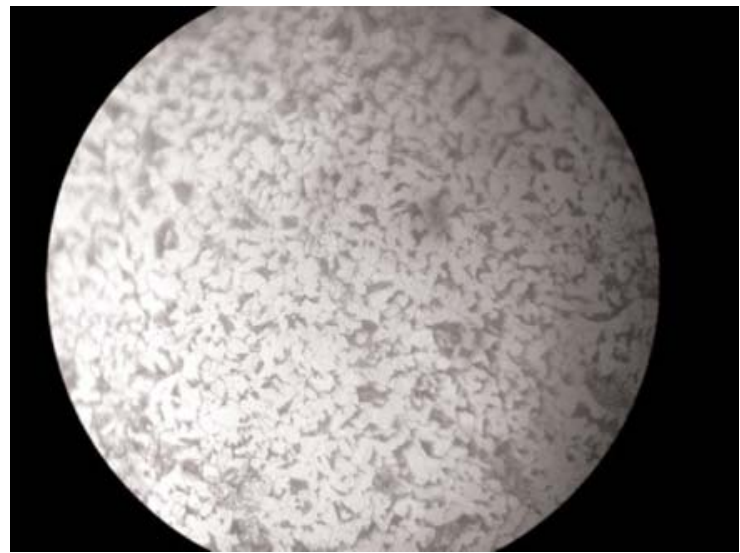

3(b): seat stays: normalized mild steel 


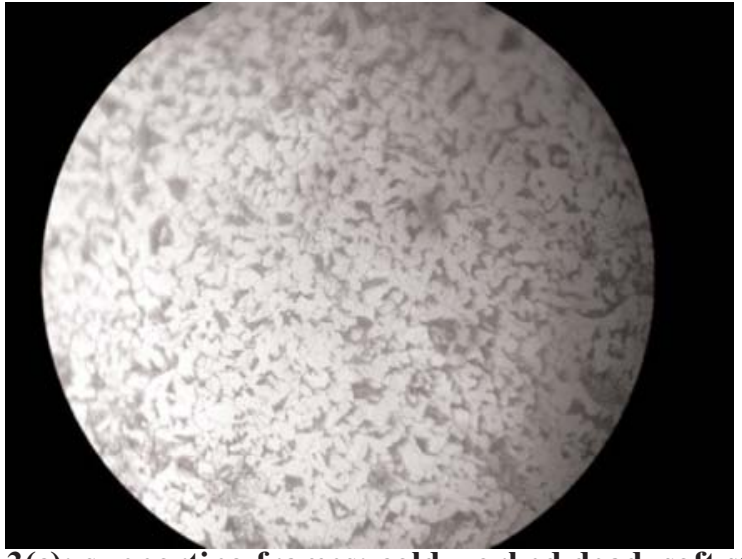

3(c): supporting frames: cold worked dead soft steel

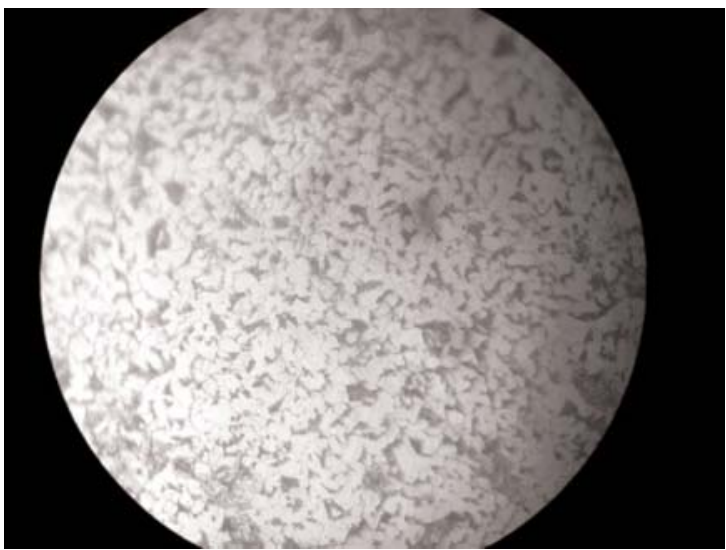

3(d): axle: cold rolled mild steel

Fig. 3: Microstructure of the different parts of frame

Failure is most susceptible in the joint region in top tubes, shown in Figure 4. Dead soft steel is a soft and highly ductile material. Joining is generally done by heating the

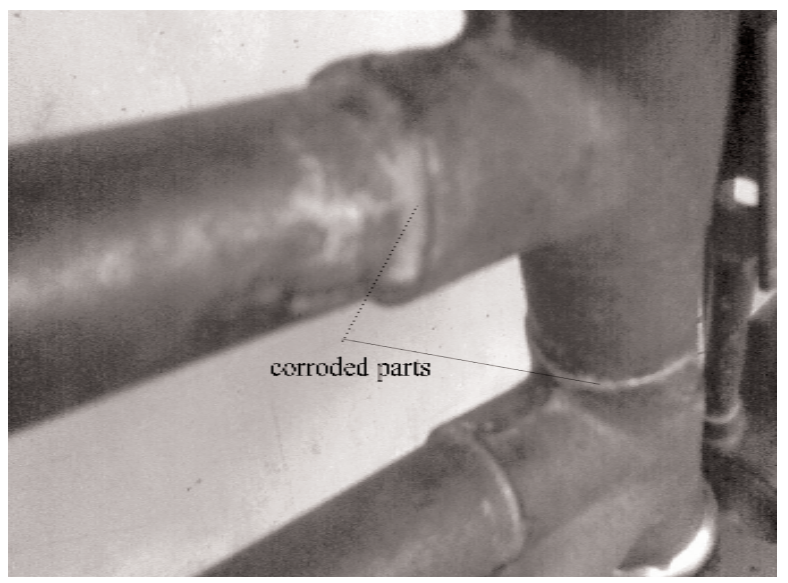

Fig. 4: Corrosion occurring at the joints in the top tube tubes and thus joining with the lug. Failure mechanism has been identified as a fretting fatigue failure in that region. Due to the repeating loading and the soft structure of the tube, fretting may occur by some loosening of small particles at the contact of the tube and the lug, and may be by some oxide particle formation at the joint due to the coating removal at that area. Also, there is a compressive force at that area by the rickshaw puller and a repeating vibration force from the road causes fatigue at that area. Using gasket at the tight fit lug and tube, proper coating, using lubricating and selecting mild steel instead of dead soft steel may significantly increase the life cycle of the tube.

In the axle, the failure has also been identified due to fatigue. Failed samples of axle are shown in Figure 5 (a) and 5 (b). In Figure 5 (b), the fractured sample is seen to have two

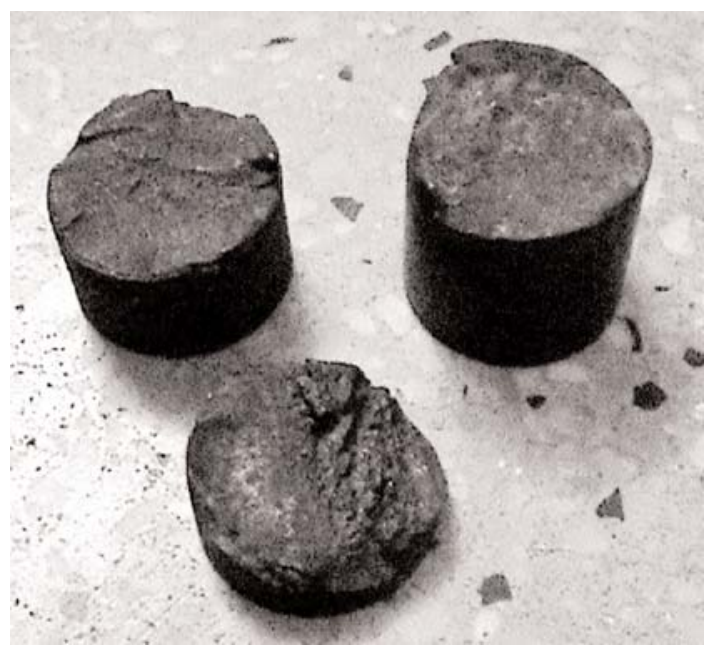

5(a): Three fractured samples

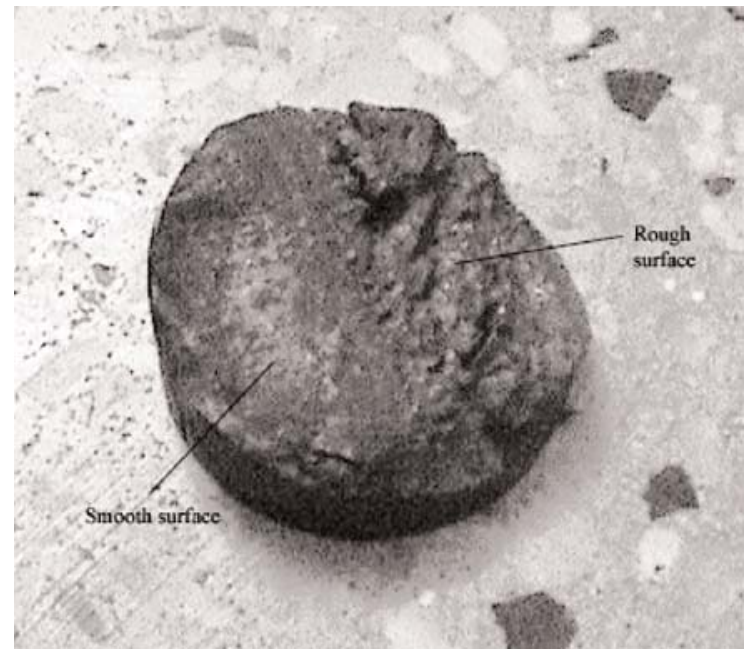

5(b): Sample showing smooth and rough surface

Fig. 5: Fractured samples of the axle 
regions; smooth bright surface and other is a rough surface. From the analogy of the fractured surfaces of the samples and also from the scanning electron microscopic (SEM) observation in Figure 6, it can be concluded that the failure is due to fatigue. The fractured surface is almost flat as seen in the SEM micrograph and resembles somewhat like brittle fracture. There are some holes, but is not deep enough to be said as pit. These holes developed during fracture. alloy (AZ91E), Al alloy (7075-T6), Ti alloy (Ti-6Al-4V) had been used in the frame system of the bicycle and consequently, has been considered in our study (Manshadi et al., 2007).

\section{Costs per unit property method}

If one property is very important in the design criteria, cost per unit property method can be taken as good reference for further culling of materials from the preliminary list (Farag,

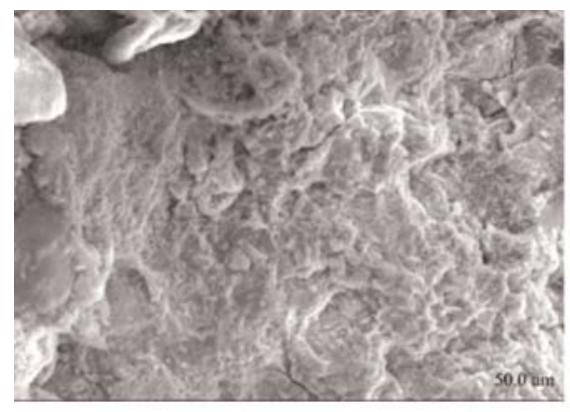

6(a): $50 \mu \mathrm{m}$ region, magnified $1000 \mathrm{x}$

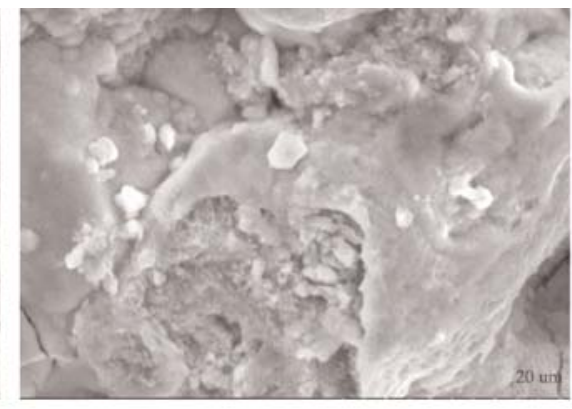

6(b): $20 \mu \mathrm{m}$ region, magnified $2500 \mathrm{x}$

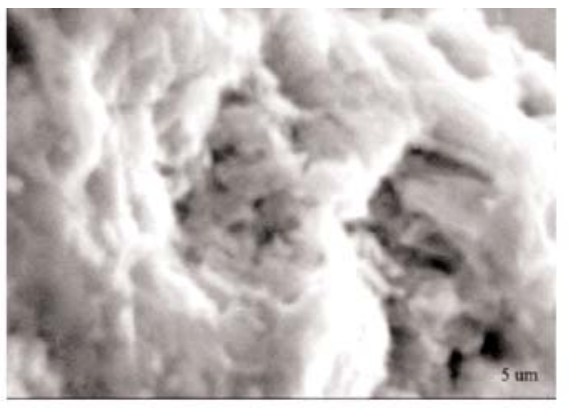

6(c): $5 \mu \mathrm{m}$ region, magnified $10000 \mathrm{x}$

Fig. 6: SEM micrograph of the fractured surface at various magnifications

\section{Initial selection of materials}

Ashby's material selection chart was used to narrow down the field of materials from the vast amount. All the materials which lie on the line of the performance maximizing criteria, in the Ashby's Young's modulus versus density curve, is equally well in performance; those above the line is better and those furthest from the line are the best (Ashby, 1992). Substituting the constraints of performance index in the Ashby's chart in Figure 7, the materials that fulfill the criterion are shown in Table I.

Table I: Preliminary selected materials

\begin{tabular}{l|c|c|c}
\hline Metals & $\begin{array}{c}\text { Engineering } \\
\text { Ceramics }\end{array}$ & $\begin{array}{c}\text { Engineering } \\
\text { composites }\end{array}$ & Woods \\
\hline Mg alloy & $\mathrm{SiC} \mathrm{Si}_{3} \mathrm{~N}_{4}$ & CFRP & Oak \\
Steel & $\mathrm{ZrO}_{2}$ & KFRP & Pine \\
Al alloy & $\mathrm{Al}_{2} \mathrm{O}_{3}$ & GFRP & Fir \\
Ti alloy & Sialons, etc. & & Balsa, etc \\
\hline
\end{tabular}

However, from this list, engineering ceramics is easily eliminated due to their extreme brittleness and will be inappropriate for the frame system of the rickshaw. Wood can be a reasonable choice for a light, stiff beam; but the problem is with the environmental consideration and also mass production. For this, wood is also eliminated in the selection process. $\mathrm{Mg}$
2002). High strength to weight ratio is an important consideration in the frame material selection of rickshaw. The Table II gives an overview of the cost per unit strength values for different materials. Relative cost has been considered from Ashby's chart shown in Figure 8. Here, working stress has been considered with taking a factor of safety 3 of the yield strength.

Steel has been found the lowest cost per unit strength property. On the contrary, CFRP is seen to attain the highest cost per unit strength value followed by titanium. If cost is the primary concern in the design process, these two materials can be easily eliminated for the further analysis. However, for the performance observation, these two materials have been considered in the later section.

\section{Weighted property method}

If there are a large number of properties to be considered, each property is assigned a certain weighting factor depending on the importance of that property. A weighted property value is obtained by multiplying the numerical value of the property by the weighting factor $(\alpha)$. Material performance index $(\gamma)$, thus obtained by summing up of the individual weighted properties values (Farag, 2002). 


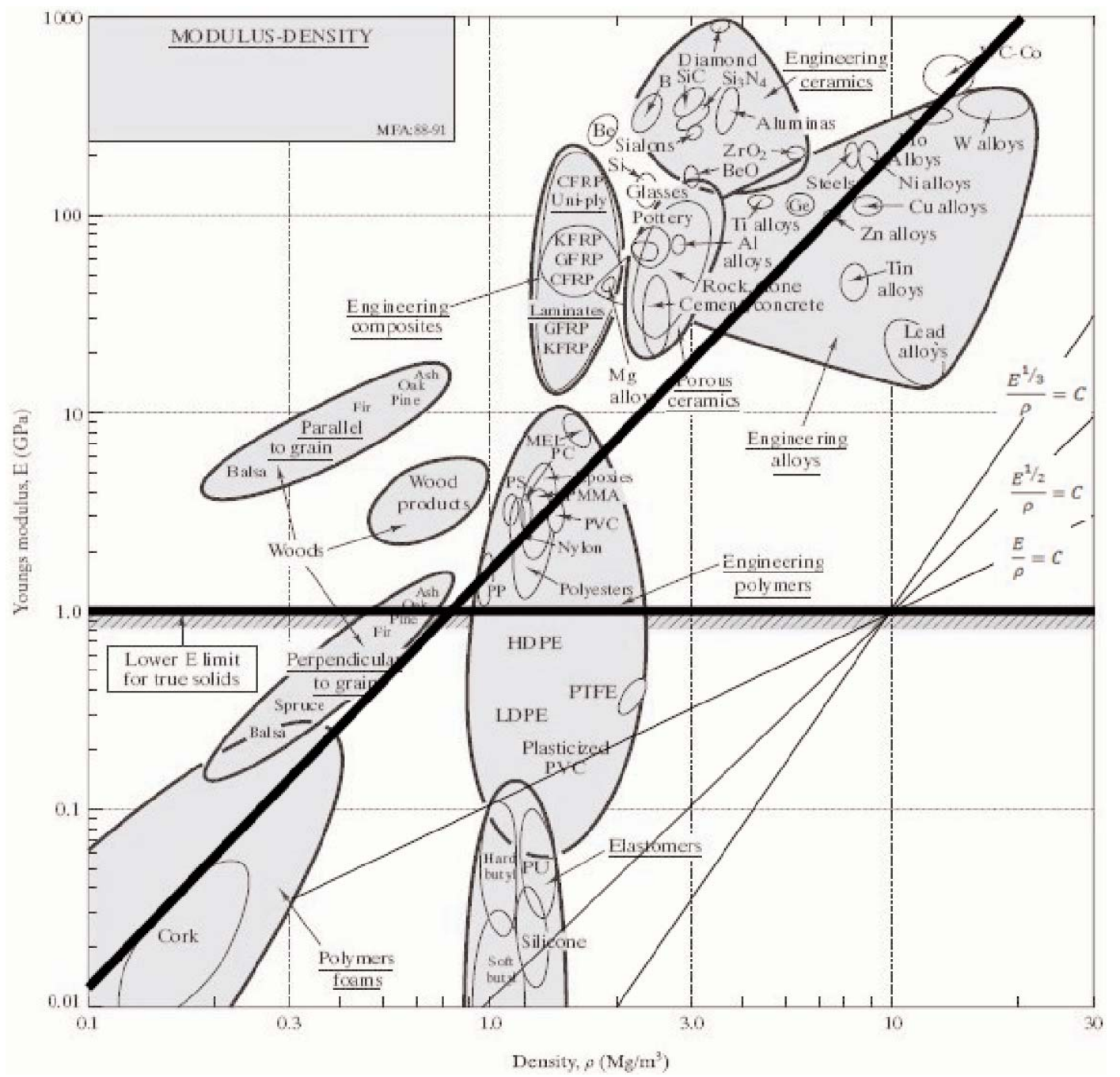

Fig. 7: Ashby's young modulus versus density curve

This weighting factor can be determined through the Digital logic approach, where only two properties are considered at a time and only a yes or no decision is considered. The most important property is given a numerical value 1 and the least one 0 (Farag, 2002). The total no of possible decision $(\mathrm{N})$ is $\mathrm{N}=\frac{n(n-1)}{2}$, where $\mathrm{n}$ is the number of properties under consideration.

\section{Table II: Cost per unit strength determination}

\begin{tabular}{l|c|c|c|c|c}
\hline Materials & $\begin{array}{c}\text { Yield Strength } \\
(\mathrm{MPa})\end{array}$ & $\begin{array}{c}\text { Working Stress } \\
(\mathrm{MPa})\end{array}$ & $\begin{array}{c}\text { Specific Density } \\
\left(\mathrm{Kg} / \mathrm{m}^{3}\right)\end{array}$ & $\begin{array}{c}\text { Relative cost per unit } \\
\text { volume }(\mathrm{C} \rho)\left(\$ / \mathrm{m}^{3}\right)\end{array}$ & $\begin{array}{c}\text { Cost/unit } \\
\text { strength }\end{array}$ \\
\hline Mg alloy (AZ91E) & 145 & 48.333 & 1.81 & 18 & 0.372 \\
Ti-6Al-4V & 828 & 276 & 4.42 & 7.7 & 10 \\
Steel AISI 1018 & 386 & 128.667 & 2.81 & 18 & 0.525 \\
Al alloy (7075-T6) & 503 & 167.667 & 1.61 & 180 & 0.077 \\
CFRP & 670 & 223.333 & 1.4 & 60 & 0.806 \\
KFRP & 621 & 207 & 1.8 & 20 & 0.289 \\
GFRP & 125 & 41.667 & & 0.480 \\
\hline
\end{tabular}




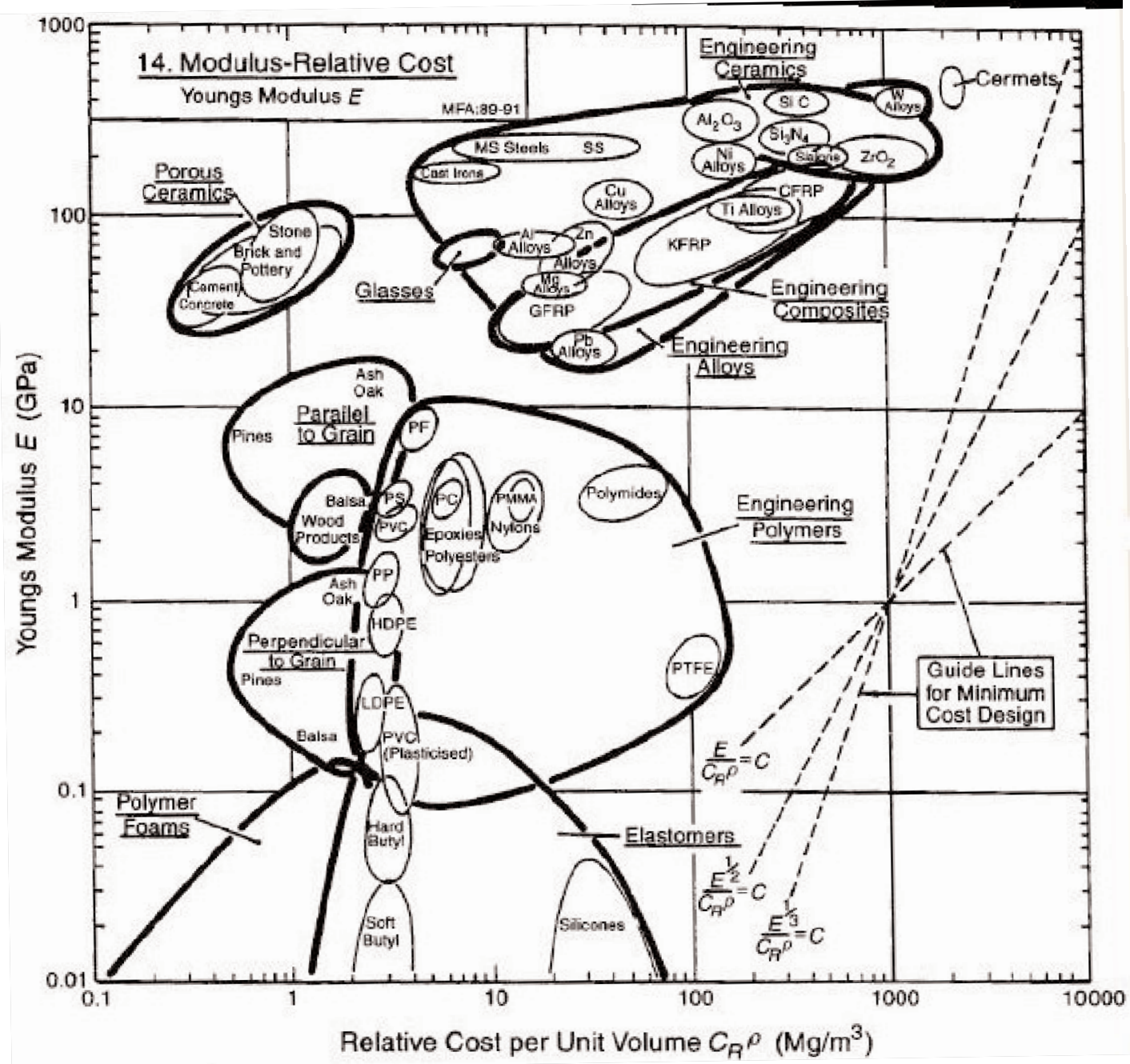

Fig. 8: Ashby's young modulus versus relative cost per unit volume chart

The modification of the digital logic method is also available in various forms. In the modified method, the values may be assigned from 0 to 3 . The most important property value being assigned 3 and the numerical value is gradually decreased with the lowering of importance of the property (Farag, 2002). In our study, we approached with modified digital logic method, where the least property value is assigned the value 0 and the highest property as 2 . When both properties seem to have equal importance, both two properties have been assigned the value 1. Similarly, when one property seems to have higher impact than the other, the values are assigned generally 2 and 1, or 1 and 0 according to their relative importance.

Weighting factor has been estimated in the modified form in Table III. Yield strength can be easily considered the highest importance than that of tensile strength during these two properties consideration. Similarly, when only toughness and tensile strength properties are required in a rickshaw frame, toughness is more desirable than that of tensile strength; but both two of these properties are required. Hence, these properties has been assigned the number generally 2 and 1 .

Seven properties were considered for the weighting factor determination as shown in Table III. Tensile and yield strength is a relative representation of the compression or buckling load on the tubes. The materials under consideration in this study have the same value of compression as in tension. Elastic modulus, toughness and fracture toughness represents the relative stability of the frames during bending load. Fatigue strength has been considered for the long cycle loading on the frames and the specific density is for lowering the weight thus improving the rickshaw puller's perform 
Table III: Modified digital logic implication on determination of relative importance of various properties

\begin{tabular}{|c|c|c|c|c|c|c|c|c|c|c|c|c|c|c|c|c|c|c|c|c|c|}
\hline \multirow[t]{2}{*}{ Properties } & \multicolumn{21}{|c|}{ Number of decisions } \\
\hline & 1 & 2 & 3 & 4 & 5 & 6 & 7 & 8 & 9 & 10 & 11 & 12 & 13 & 14 & 15 & 16 & 17 & 18 & 19 & 20 & 21 \\
\hline Tensile strength & 0 & 0 & 1 & 1 & 1 & 1 & & & & & & & & & & & & & & & \\
\hline Yield strength & 2 & & & & & & 2 & 1 & 2 & 2 & 2 & & & & & & & & & & \\
\hline Elastic modulus & & 2 & & & & & 1 & & & & & 2 & 2 & 2 & 2 & & & & & & \\
\hline Toughness & & & 2 & & & & & 2 & & & & 1 & & & & 1 & 0 & 1 & & & \\
\hline Fatigue Strength & & & & 0 & & & & & 0 & & & & 1 & & & 0 & & & 1 & 1 & \\
\hline Specific density & & & & & 1 & & & & & 0 & & & & 0 & & & 1 & & 0 & & 2 \\
\hline Fracture toughness & & & & & & 0 & & & & & 0 & & & & 1 & & & 0 & & 1 & 0 \\
\hline
\end{tabular}

ance. The resulting weighting factor was determined by dividing the number of positive decisions against that property by the total number of positive decisions.

Yield strength and elastic modulus was seen to have the highest weighting factor followed by toughness in Table IV. Hence, in the determination of material performance index, these three properties had the cardinal influence. The next step in the performance index determination through weighted property method was to determine the scaled property of the materials. Scaled property facilitates the conversion of different material properties to the scaled dimensionless value. Here, one property was considered at a time for a list of different materials. The highest value of that property in those materials was considered in a scaling property as 100 and the scaled value of other materials was calculated according to equation (3).

Scaled property $=\frac{\text { Numerical value of property }}{\text { Maximum value in the list }} \times 10 \ldots . .(3)$

Table IV: Weighting factor of different properties

\begin{tabular}{l|c|c}
\hline Properties & $\begin{array}{c}\text { Number of positive } \\
\text { decisions }\end{array}$ & $\begin{array}{c}\text { Weighting factor } \\
(\alpha)\end{array}$ \\
\hline Tensile strength & 4 & 0.095 \\
Yield strength & 11 & 0.262 \\
Elastic modulus & 11 & 0.262 \\
Toughness & 7 & 0.167 \\
Fatigue strength & 3 & 0.071 \\
Specific density & 4 & 0.095 \\
Fracture toughnes & 2 & 0.048 \\
\hline
\end{tabular}

Total $=42$

However, for properties like specific density, cost, corrosion or wear loss, etc., the lowest value of a specific property was given in a scaling value 100 and the calculation of the scaling properties of other materials is done according the equation (4).
Scaled property $=\frac{\text { Minimum value in the list }}{\text { Numerical value of property }} \times 10 \ldots$.

Different property values of the preliminary selected material for the rickshaw frame system are given in Table $\mathrm{V}$ (Maleque et al., 2010; www.carbonfiber.gr.jp; aluminum. matter. org.uk). The calculated scaled property value of the selected materials is expressed in Table VI. The material performance index from this scaled value of the properties can be calculated by equation (5).

Material performance index, $\gamma=\sum_{i=1}^{n} B_{i} \alpha_{i}$

Where B is the scaled property, $\alpha$ is the weighting factor; the number of properties considered, $n=7$

If the selection would be based on only performance characteristics without any kind of cost consideration, CFRP would be the best material to substitute steel followed by titanium. The performance index values can be expressed as a chart, shown in Figure 9. KFRP and aluminum alloy also shows a good performance index value after steel. The inferior in performance are the GFRP and the Mg alloy. However, cost is the most important factor in the material selection process of rickshaw frame. As the important function of the frame materials is to bear stress, cost of unit strength may be introduced in figure of merit calculation and is defined as is given in equation (6). Table VII shows the estimated figure of merit of the different materials.

Figure of merit, $M=\frac{\text { Performance index, } \gamma}{\text { Cost per unit strength, } C}$

After the cost consideration therefore, yield steel AISI 1018 the best candidate for the rickshaw frame system followed by aluminum alloy and KFRP. CFRP and titanium although have the best performance indices, cost consideration has made these two materials far behind of steel. Figure of merit 
Table V: Property values of the selected materials

\begin{tabular}{|c|c|c|c|c|c|c|c|}
\hline Materials & $\begin{array}{l}\text { Tensile } \\
\text { Strength } \\
\text { (Mpa) }\end{array}$ & $\begin{array}{c}\text { Compressive } \\
\text { yield } \\
\text { strength }(\mathrm{MPa})\end{array}$ & $\begin{array}{l}\text { Elastic } \\
\text { Modulus } \\
(\mathrm{GPa})\end{array}$ & $\begin{array}{l}\text { Toughness }{ }^{1} \\
\left(\mathrm{MN} \mathrm{m}^{3 / 2}\right)\end{array}$ & $\begin{array}{l}\text { Specific } \\
\text { Density } \\
\left(\mathrm{Kg} / \mathrm{m}^{3}\right)\end{array}$ & $\begin{array}{c}\text { Fatigue Strength, } \\
\mathrm{MPa}\left(5 \times 10^{7}\right. \\
\text { cycles })\end{array}$ & $\begin{array}{c}\text { Fracture } \\
\text { Toughness } \\
\left(\mathrm{MPa} \mathrm{m}^{1 / 2}\right)\end{array}$ \\
\hline $\begin{array}{l}\text { Cast } \mathrm{Mg} \text { alloy } \\
\text { (AZ91E) }\end{array}$ & 275 & 145 & 45 & 25 & 1.81 & 70 & 13.2 \\
\hline Ti-6Al-4V & 897 & 828 & 114 & 179 & 4.42 & 290 & 90 \\
\hline Steel AISI 1018 & 634 & 386 & 190 & 145 & 7.7 & 173 & 82 \\
\hline Al alloy (7075-T6) & 572 & 503 & 71.7 & 90 & 2.81 & 151 & 20 \\
\hline CFRP & 1725 & 670 & 158.7 & 60 & 1.61 & 520 & 65 \\
\hline KFRP & 1380 & 621 & 76 & 39 & 1.4 & 245 & 38 \\
\hline GFRP & 530 & 125 & 26 & 40 & 1.8 & 38 & 23 \\
\hline
\end{tabular}

Table VI: Performance index determination

\begin{tabular}{l|c|c|c|c|c|c|c|c}
\hline \multirow{2}{*}{ Materials } & \multicolumn{7}{|c|}{ Scaled Properties } & $\begin{array}{c}\text { Performance } \\
\text { Index }(\gamma)\end{array}$ \\
\cline { 2 - 8 } & 1 & 2 & 3 & 4 & 5 & 6 & 7 & 22.11 \\
Cast Mg alloy & 15.94 & 17.51 & 23.68 & 13.97 & 77.35 & 13.46 & 14.67 & 100.00 \\
Ti-6Al-4V & 52.00 & 100.00 & 60.00 & 100.00 & 31.67 & 55.77 & 75.91 \\
Steel AISI 1018 & 36.75 & 46.62 & 100.00 & 81.01 & 18.18 & 33.27 & 91.11 & 64.26 \\
Al alloy (7075-T6) & 33.16 & 60.75 & 37.74 & 50.28 & 49.82 & 29.04 & 22.22 & 44.71 \\
CFRP & 100.00 & 80.92 & 83.53 & 33.52 & 86.96 & 100.00 & 72.22 & 77.32 \\
KFRP & 80.00 & 75.00 & 40.00 & 21.79 & 100.00 & 47.12 & 42.22 & 54.97 \\
GFRP & 30.72 & 15.10 & 13.68 & 22.35 & 77.78 & 7.31 & 25.56 & 21.63 \\
\hline
\end{tabular}

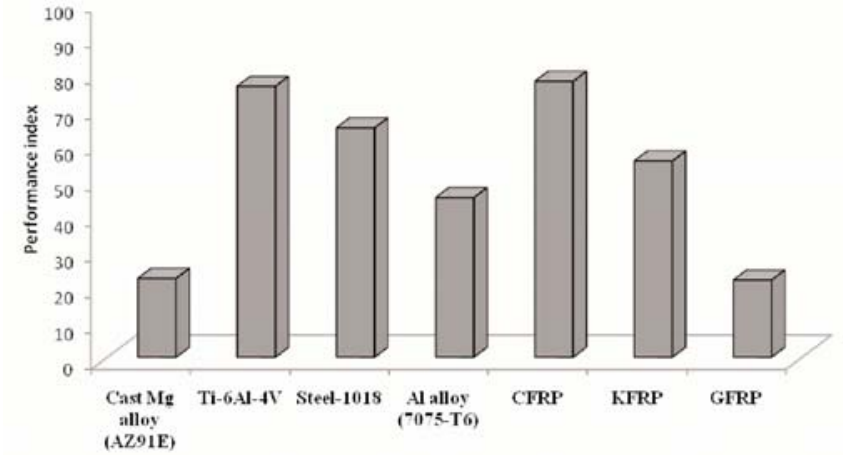

Fig. 9: Performance index values of the selected materials

values of different materials is expressed in a column chart in Figure 10. Also, a comparison has been shown in Table VIII with steel for aluminum and KFRP.

\section{Manufacturing Issues}

In terms of figure of merit, the optimum material is the existing steel AISI 1018 followed by Al alloy and KFRP. However for any kind of material selection, manufacturing issue is another term which also has to be considered.
Although, steel comes out the best material in the selection process, but the high weight still will remain a problem. This is somewhat can be minimized by varying the thickness in different section of the tube in terms of stress concentration. In the rickshaw frame material selection, two things are important. One is the making of thin walled section and the other is joining the sections together. It is possible to make

Table VII: Figure of merit estimation

\begin{tabular}{l|c|c|c}
\hline Materials & $\begin{array}{c}\text { Cost per unit } \\
\text { strength, } \\
\mathrm{C} \times 100\end{array}$ & $\begin{array}{c}\text { Performance } \\
\text { index, } \gamma\end{array}$ & $\begin{array}{c}\text { Figure } \\
\text { of merit, M }\end{array}$ \\
\hline Cast Mg alloy & 37.24 & 22.11 & 0.59 \\
(AZ91E) & 52.54 & 75.91 & 1.44 \\
Ti-6Al-4V & 7.77 & 64.26 & 8.27 \\
Steel AISI 1018 & 10.74 & 44.71 & 4.16 \\
Al alloy (7075-T6) & 80.60 & 77.32 & 0.96 \\
CFRP & 28.99 & 54.97 & 1.90 \\
KFRP & 48.00 & 21.63 & 0.45 \\
GFRP &
\end{tabular}


Table VIII: Performance, weight and relative cost comparison of aluminum alloy and KFRP with steel

\begin{tabular}{l|c|c|c}
\hline Materials & Performance & Weight per unit volume & Relative cost per unit volume \\
\hline Aluminum alloy & $30.42 \%$ decrease & $63.5 \%$ decrease & $80 \%$ increase \\
KFRP & 9.29 decrease & $81.8 \%$ decrease & 5 times more than steel \\
\hline
\end{tabular}

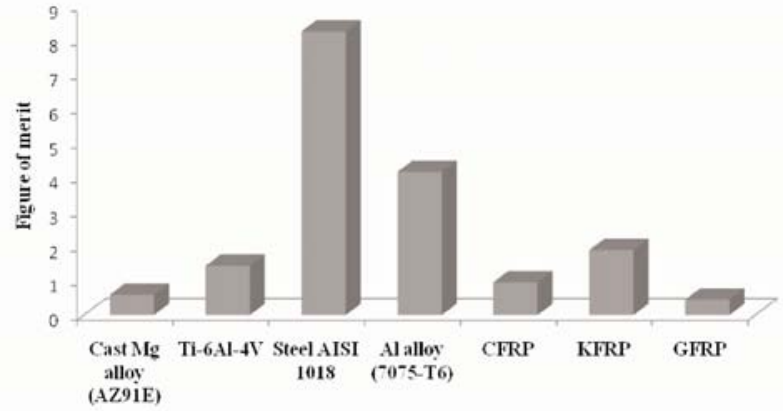

Fig. 10: Figure of merit values of the selected materials

low thickness tube by extrusion in steel and aluminum alloy. Heating the tube, using gasket in the tube front and then joining with the lug with proper coating application can longer the frame life. Arc welding is usually straightforward for joining the tubes into the rickshaw frames for these two materials. Composite materials, i.e., CFRP, KFRP and GFRP are difficult to join. The tubes made of these materials may be joined with adhesives and lugs, in a method somewhat analogous to lugged steel frames. Alternatively, these materials can also be produced in a single piece, called monocoque construction (Manshadi et al., 2007). This joining difficulty has increased the processing cost of the composites.

\section{Conclusion}

Study on the material selection alternatives in rickshaw frame system was done by Ashby's material selection chart, cost per unit property method and weighted property method with the assistance of modified digital logic method. The study precedes the following concluding statements:

1. Steel is the optimum material to be used in the rickshaw frame system.

2. Aluminum alloy and KFRP come next to steel in terms of figure of merit for the frames.

3. CFRP and Titanium alloys are the best materials in terms of performance index, but the cost consideration has limited their use and hence very low figure of merit.

\section{Acknowledgement}

Authors wish to acknowledge whole heartedly to the director of the Institute of Mining, Mineralogy and Metallurgy (IMMM), Sudhangshu Kumar Ray for his encouragement and kind suggestion, Metallurgy Division of IMMM and
Dhaka Lab of Bangladesh Council of Scientific and Industrial Research for their help and cooperation offered during this study.

\section{References}

Ashby M. F., Bre'chetb Y. J. M., Cebon D. and Salvo L. (2004). Selection strategies for materials and processes, Materials and Design, 25: 51-67.

Ashby M. F. (1992). Material selection in mechanical design, 2nd edition, (Butterworth-Heinmann, Oxford), pp 1-205.

aluminium. matter.org.uk/content/html/eng/default.asp

Farag M. M. (2002). Handbook of material selection, 2nd edition, (John Wiley \& Sons Inc., New York), pp 3-24.

Farag M. M. and Magid E. E. (1992). An integrated approach to product design, materials selection and cost estimation, Materials and Design, 13(6): 243-248.

Jahazi M. and Nejad S. H. (2004). The development of an optimum manufacturing and material selection process for the fabrication of labyrinth seal strips, Journal of Materials Processing Technology, 152: 272-275.

Maleque M. A. and Dyuti S. (2010). Material for bicycle frame system-A case study on the development of selection method, 3rd Int. Conference on structure, processing and properties of materials, , H01, SPPM 24-26 February, 2010, Dhaka, Bangladesh (CD version).

Manshadi B. D., Mahmudi H., Abedin A. and Mahmudi R. (2007). A novel method for materials selection in mechanical design: Combination of non-linear normalization and a modified digital logic method, Materials and Design, 28: 8-15.

Menchetti P. and Hendrikkade P. (2005). Cycle Rickshaws in Dhaka, Bangladesh, Amsterdam social movements \& collective action, Thesis for Amsterdam University, 78-189.

Pytel A. and Singer F. L. (1987). Strength of Materials, 4th edition, (Harper \& Row publishers), pp 47-123.

www.carbonfiber.gr.jp/english/tanso/03.html

Received: December 13, 2009;

Accepted : April 25, 2011 